\title{
Shared Mobility Services in Malta: User Needs and Perceptions
}

\author{
Suzanne Maas and Maria Attard
}

\begin{abstract}
Malta is a small island state home to nearly half a million inhabitants. It is a major tourist destination in the Mediterranean, with visitor numbers totalling 2.6 million in 2018. There are 799 vehicles for every thousand inhabitants and the modal split shows a $74.6 \%$ reliance on the car. Ownership and use of private cars are at an all-time high in Malta. This dependence on the car has increased congestion and given rise to parking issues in many localities, taken-up limited space in the urban area, increased air and noise pollution, and created accessibility problems for pedestrians and cyclists. Shared mobility services (bicycle, car, scooter sharing) have been introduced in Malta very recently. Malta is one of the case study sites in the CIVITAS DESTINATIONS project, which focused on sustainable mobility in tourist destinations. As part of the project, a survey was conducted to understand the awareness and acceptance of these shared mobility services by Maltese residents ( $n$ $=1,100)$. Insights from this survey used to understand user needs and perceptions in light of such mobility innovations and what might encourage people to start using them as an alternative to private car use.
\end{abstract}

Keywords Shared mobility $\cdot$ Travel behaviour $\cdot$ Bicycle sharing $\cdot$ Sustainable mobility $\cdot$ Car sharing

\section{Introduction}

Malta is an EU member state with a land area of $316 \mathrm{~km}^{2}$ and was home to a population of 460,297 in 2016 (NSO, 2018). Malta lies in the middle of the Mediterranean Sea and includes the main island Malta, Gozo and Comino. Car ownership and use are at an unprecedented high level with 799 cars per thousand (NSO, 2017) and private car use topping the modal share with $74.6 \%$ of all trips (Transport Malta, 2011).

S. Maas $(\bowtie) \cdot$ M. Attard

Institute for Climate Change and Sustainable Development, University of Malta, Msida, Malta

e-mail: suzanne.maas@um.edu.mt

M. Attard

e-mail: maria.attard@um.edu.mt 

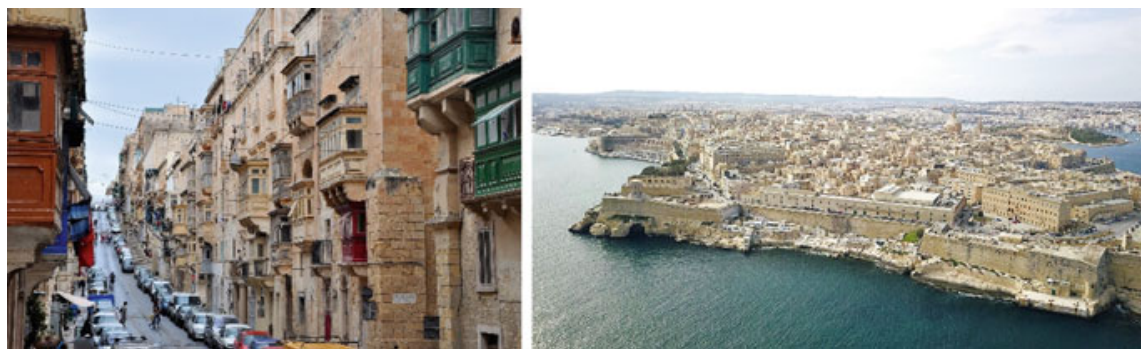

Fig. 1 Valletta, the capital city of Malta. Steep streets characterize the city (left; photo by Herbert Frank, licensed under CC BY-ND 2.0), built on a peninsula between two natural harbours: the Grand Harbour and Marsamxett (right; photo by Dion Hinchcliffe, licensed under CC BY-SA 2.0)

Despite all this, the average trip distance is just $5.5 \mathrm{~km}$ (Transport Malta, 2016a). As other Mediterranean coastal cities, Malta's capital Valletta, as well as the broader conurbation around the harbour areas, is characterized by its historic centres and a tight spatial urban fabric that is poorly suited to the needs of car-based mobility (Cavallaro et al., 2017) (see Fig. 1). The transport system and infrastructure are under pressure from the heavy reliance on the private car, and in addition to the daily movements of a medium-sized city, such as for work, education and leisure, the transport system has to provide for seasonal tourism, especially during the summer months. As a result of high car dependence, there are pressing issues related to traffic, congestion, parking, noise and air pollution, and overall accessibility concerns for active road users. In a special Eurobarometer survey on attitudes of Europeans towards urban mobility, Maltese citizens were the most likely of all respondents in the Member States to highlight road congestion (97\%), noise pollution (92\%) and air pollution (95\%) as important challenges (European Commission, 2013). However, due to Malta's small size and highly urbanized morphology, it may be more sensible to compare such statistics with other major cities, rather than with other European countries (Transport Malta, 2011). In Malta, transport contributes to over $20 \%$ of $\mathrm{CO}_{2}$ emissions (Attard et al., 2015). Encouraging alternative modes of transport is not only beneficial for the well-being of local residents, in terms of reduced pollution, traffic and congestion, but can also increase the attractiveness of a destination for tourists and contribute to a better tourist experience (Le-Klähn \& Hall, 2015). Shared solutions in transport, for example, (electric) bicycle and car sharing, are example of transport alternatives put forward to mitigate against the external costs of traffic and improve mobility and accessibility. 


\section{Sustainable Mobility and Sharing Services}

The avoid-shift-improve approach is often used to guide sustainable mobility policy (Ang \& Marchal, 2013; Jonuschat et al., 2015). It provides a list of priorities for sustainable mobility. Firstly, by avoiding the need to travel far by investing in a mix of land uses at the local scale and create more dense developments, and by adopting technology to substitute trips through online communications and teleconferencing. Secondly, by shifting trips to green alternative modes, such as walking and cycling, promoting the use of public transport and encourage shared mobility. Lastly, by improving vehicle and fuel technologies and using electric, hybrid or hydrogen-fuelled vehicles which pollute less. The concept of shared mobility can be positioned as a manner that shifts mobility from individual travel to shared travel, increasing efficiency and reducing consumption. Shared mobility has the potential to provide flexible, short-term, as-needed access to mobility, as an alternative to private transport, or can be used for last-mile trips in conjunction with public transport, or as part of a multi-modal solution (Jonuschat et al., 2015; Shaheen \& Chan, 2016). The widespread uptake in smartphones, combined with GPS positioning technology, increased Internet coverage, and the use of social networks has enabled people to connect, share and exchange information in new and easier ways, and has enabled the growth of shared mobility services (DeMaio, 2009; Shaheen \& Chan, 2016). Shared mobility is generally understood to refer to both the sharing of a vehicle and the sharing of rides (Shaheen \& Chan, 2016). In this chapter, the focus is on shared vehicles: (e-)bicycle and car sharing.

\subsection{Bicycle- and Car-Sharing Systems}

Bicycle-sharing systems can be classified as station based or dockless. In the former, users can rent and return bicycles from docking stations, generally from any station (although there are systems where bicycles can only be returned to the station they have been rented from). The latter refers to free-floating systems without fixed stations. Here users can find and rent a bicycle using a smartphone app within a well-defined, geofenced area (DeMaio, 2009; Fishman, 2016). Car sharing can take different forms, either in a fixed, station-based car-sharing system, where the car is checked-out and checked-in at the same location; in a flexible, free-floating system, a one-way car-sharing system in which you can book a car through an app from any location within a certain area and through peer-to-peer sharing, whereby private individuals can rent a car from another private individual through a transaction on an online platform (Jonuschat et al., 2015). Some car- and bicycle-sharing providers are now also providing additional transport options, such as shared scooters, as well as electric vehicles and bicycles (Shaheen \& Chan, 2016).

Benefits of shared mobility services over private vehicles exist on different levels, for the individual, the transport operator and/or authority, and society as a whole 
(Shaheen et al., 2010). For users, shared mobility can offer on-demand, flexible and increased mobility options, travel time and cost savings, and health benefits from physical activity while using bicycle sharing (Ricci, 2015; Shaheen et al., 2010). From the operator or local transport authority's perspective, shared mobility systems can provide a more efficient and low-cost alternative to investing in infrastructure for private vehicles or increased capacity for public transport (Castillo-Manzano et al., 2015; Shaheen et al., 2010). For society, benefits range from reduced congestion and improved environmental quality (reductions in air pollution and carbon emissions) resulting from mode shift and reduced private vehicle ownership (Martin \& Shaheen, 2011; Shaheen \& Chan, 2016), to public health improvements as a result of increased physical activity by the population (Woodcock et al., 2014; Fishman, 2016).

\subsection{Shared Mobility in Malta}

Malta's National Transport Strategy 2050 promotes active travel and shared mobility which are some of the guiding principles to encourage a modal shift towards sustainable transport modes (Transport Malta, 2016b). Transport Malta put forward the idea of introducing car and bicycle-sharing services in their Transport Master Plan 2025, which contains a set of measures for the shorter term. In this policy, bicycle sharing is put forward as an alternative means of travelling in the busy urban centre around the capital city Valletta, and is expected to normalize cycling in Malta for both local residents and tourists. Car sharing is suggested as a solution to improve the efficiency of vehicle use, by sharing a fleet of cars instead of relying on private vehicles (Transport Malta, 2016a). In the last few years, (e-)bicycle- and car-sharing services were introduced in Malta. Figure 2 shows the geographic distribution of the station-based (e-)bicycle- and car-sharing services (as per April 2019). Other shared mobility services, such as free-floating electric (moto)scooters, as well as ride-pooling and sharing services, have been introduced since, but were not present at the time of this research and were therefore not considered in the surveys.

The first shared mobility service to be introduced on the islands was the bicyclesharing system implemented by Nextbike Malta. It was introduced in 2016, with a total of 58 stations and just over 400 bicycles. Many of the stations are located in the Northern Harbour area to the north of Valletta. This area also houses the towns of St. Julian's and Sliema which are tourist and entertainment centres, the residential and employment centres of Msida and Gżira, as well as the campus of the University of Malta in Msida. Pay-as-you-go fees for casual users are $€ 1.50$ for the first $30 \mathrm{~min}$ and $€ 1$ for every consecutive $30 \mathrm{~min}$. Subscribed users, with a weekly (€15), monthly $(€ 25)$, quarterly (€35) or yearly (€80) membership, can use the system for free for the first half-hour, after which they pay the regular fee. Stations in St. Paul's Bay also offer electric bicycles, even though the cost for these is higher ( $€ 3$ for the first half-hour, $€ 2$ for every consecutive half-hour) (Nextbike Malta, 2019). Malta's public transport operator introduced the Tallinja Bike system in Valletta in 2018. The system consists of 40 electric bicycles at three stations (central bus station, ferry 


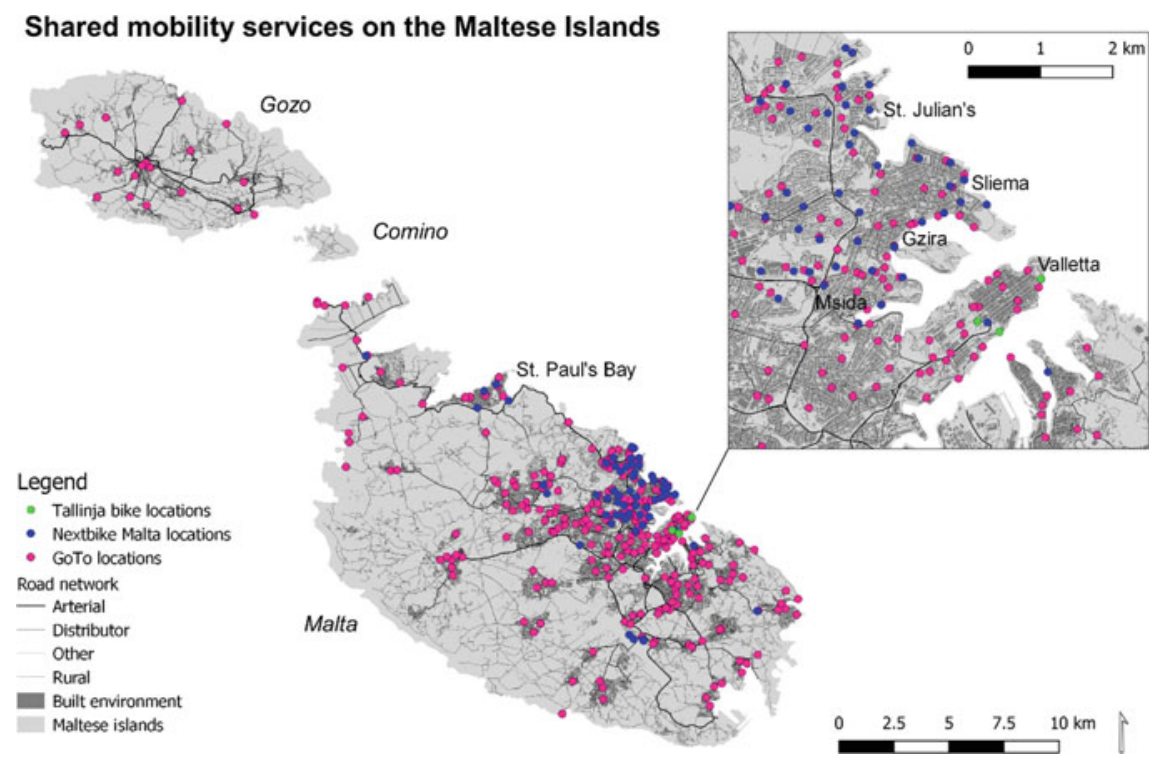

Fig. 2 Distribution of shared transport services in Malta (as in April 2019)

landing site and Fort St. Elmo), with a further two stations planned for the city's main square and at another ferry landing site. The rates are $€ 3$ for the first $30 \mathrm{~min}$ and $€ 2$ for every consecutive $30 \mathrm{~min}$ (Malta Public Transport, 2019).

In 2018, Car2Go put into operation a nationwide car-sharing service (called GoTo), following a call for proposals issued by Transport Malta (the transport regulator) and the signing of a concession agreement for the provision of services. The fleet consists of 150 electric vehicles available on both islands of Malta and Gozo and more than 300 reserved parking spaces. As a member, users benefit from 400 driving minutes at $€ 99 /$ month, and a rate of $€ 0.25$ per additional minute, whereas pay-as-you-go rates are $€ 7$ per month $+€ 0.28$ per minute (Car Sharing Services Malta Ltd, 2019). The car-sharing scheme GoTo operates across the country, while bicycle-sharing system Nextbike Malta is concentrated in the main urban conurbation, including some of the major tourist destinations in Malta, and e-bicycle-sharing system Tallinja Bike is solely available in Valletta. The shared mobility sector in Malta continues to grow, with extensions being planned by the existing shared mobility services and new scooter (moto), e-kickscooter and ridesharing services being introduced. The two available bicycle-sharing systems, Nextbike Malta and Tallinja Bike, are available with a pay-as-you-go tariff, enabling use by tourists and visitors. Following feedback from users, the car-sharing provider GoTo also introduced a basic plan without a membership, with a slightly higher pay-as-you-go tariff to enable casual use, as well as a pre-paid plan specifically geared at tourists. 


\section{Methodology}

This chapter presented the results of three cross-sectional surveys to understand user needs and perceptions about shared mobility in Malta and analyse the impact of measures implemented within the H2020 CIVITAS DESTINATIONS project. This EU-funded project brings together six Southern European island cities, including Valletta, and is focused on sustainable mobility pilots in islands' urban areas to meet both residents' and visitors' transport and mobility needs (CIVITAS Initiative, 2013).

A repeated cross-sectional telephone survey was carried out in three waves to assess the people's awareness and acceptance of the new shared transport services. These included (electric) bicycle sharing and car sharing, as well as their attitudes towards cycling safety. The surveys, with a different sample in each survey wave, are representative of the Maltese population. The first wave of surveys was carried out between July and August of 2018, the second wave between January and February of 2019, and the third wave in April 2019. A total number of 1,100 respondents participated in the survey, which resulted in a $95 \%$ confidence level and $3 \%$ margin of error. The results presented in this chapter are based on the aggregated datasets from the three survey waves. The samples were split by age, gender and residential district to ensure a proportional representation of the population using a stratified random sampling strategy (Bryman, 2016). To counteract non-response, a larger sample was defined before commencing with the data collection process. Individuals over the age of 18 were invited to participate in the surveys through the use of fixed landline telephone numbers obtained from the online directory of the islands' main fixed-line provider.

The surveys contained four separate sections with 19 questions in total. Five questions related to the respondents' socio-demographic characteristics, including age, gender, locality of residence, education and employment status. Seven questions focused on awareness and acceptance of (e-)bicycle sharing and six questions on car sharing. There was only one question which focused on cycling safety. The data analysis was carried out through the use of descriptive statistics and correlation analysis using MS Excel and the open-source software R.

\section{Results}

The socio-demographic profile of the surveyed population is presented first and compared to the general population. After that, the awareness and willingness to use bicycle and car sharing are discussed, as well as the reasons provided for the respondents' positive or negative interest in using these services. Encouraging and discouraging factors, including the perceptions about cycling safety in relation to bicycle sharing, are then discussed.

The socio-demographic characteristics of the aggregated survey samples are presented in Table 1 . The sample $(n=1,100)$ is representative of the Maltese popu- 
Table 1 Survey sample characteristics

\begin{tabular}{|c|c|c|}
\hline \multicolumn{2}{|c|}{ Demographic characteristics } & \multirow{2}{*}{$\begin{array}{l}\text { Sample specifics }(n= \\
1,100) \% \\
52.7\end{array}$} \\
\hline Gender & Female: & \\
\hline & Male: & 47.3 \\
\hline \multirow[t]{6}{*}{ Age } & 18-24: & 13.6 \\
\hline & 25-34: & 12.4 \\
\hline & 35-44: & 17.0 \\
\hline & 45-54: & 15.1 \\
\hline & 55-65: & 19.0 \\
\hline & $65+:$ & 22.9 \\
\hline \multirow[t]{6}{*}{$\begin{array}{l}\text { Employment } \\
\text { status }\end{array}$} & $\begin{array}{l}\text { In full-time } \\
\text { employment: }\end{array}$ & 39.8 \\
\hline & $\begin{array}{l}\text { In part-time } \\
\text { employment: }\end{array}$ & 5.2 \\
\hline & $\begin{array}{l}\text { Housewife/ } \\
\text { Househusband: }\end{array}$ & 18.7 \\
\hline & Retired/Pensioner: & 25.4 \\
\hline & Student: & 8.4 \\
\hline & Unemployed: & 2.5 \\
\hline \multirow{5}{*}{$\begin{array}{l}\text { Highest } \\
\text { education level }\end{array}$} & No school: & 0.4 \\
\hline & Primary: & 20.1 \\
\hline & Secondary: & 12.6 \\
\hline & Post-secondary: & 51.6 \\
\hline & Tertiary: & 15.3 \\
\hline
\end{tabular}

lation in terms of age (based on 2016 data; NSO, 2018) and gender (49.7\% female, $50.3 \%$ male, in 2016; NSO, 2018), with a $95 \%$ confidence level.

The survey sought to identify the level of awareness and acceptance of bicycle and car sharing. Here, awareness is understood as being able to define bicycle and car sharing correctly (as bicycle/car rental for a period of time). Acceptance is defined as a positive response to the question 'Would you consider making use of bicycle/car sharing?'. Figure 3 shows the aggregated results of the respondents' awareness and acceptance of bicycle and car sharing, from the repeated cross-sectional surveys with Maltese residents.

Chi-square tests of the aggregated dataset were used to assess the correlation between socio-demographic characteristics (age, gender, employment and educational level) and bicycle sharing awareness and acceptance. All socio-demographic characteristics, except for gender, are significantly associated at the $95 \%$ confidence level. From the Pearson residuals of the correlation between 'age' (in age groups as presented in Table 1) and 'awareness', it becomes clear that there is a strong positive relationship between younger age groups (most pronounced in the youngest group, 18-24) and the correct answer ('bicycle rental for a period of time'), and between 


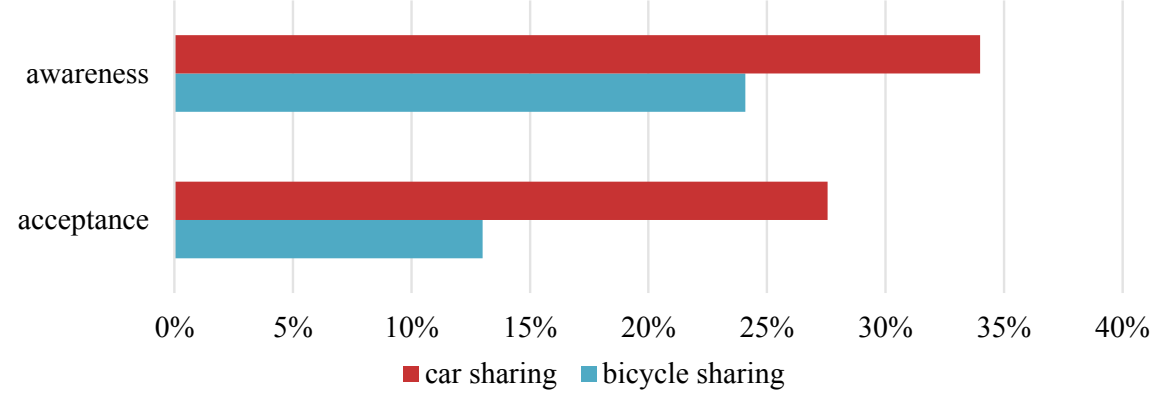

Fig. 3 Awareness and acceptance of shared mobility services by Maltese residents $(n=1,100)$

older age groups (most strongly in the oldest group, 65+) and the answer 'don't know', and vice versa (a negative association between young respondents indicating not to know, and between old respondents and the correct answer). Figure 4 visualizes the Pearson residuals of the correlation between 'age' and 'awareness', with positive residuals (indicating a positive relationship) in blue and negative residuals (indicating a negative relationship) in red. The same pattern can be observed for their willingness to use bicycle sharing, the 'acceptance'. In terms of employment status, respondents who are 'students' and 'full-time employed' are most likely to know what bicycle sharing is and consider using it, and respondents who are 'retired/pensioner' and 'housewife/husband' are the least likely.

Awareness and acceptance of bicycle sharing are also strongly correlated with education level: those with no school and those who have attended only primary school are the least likely to know what bicycle sharing is and consider using it, and those with post-secondary and tertiary education are the most likely. A positive association between bicycle-sharing use and higher education level and (full time) employment has been found in a number of studies analysing bicycle-sharing

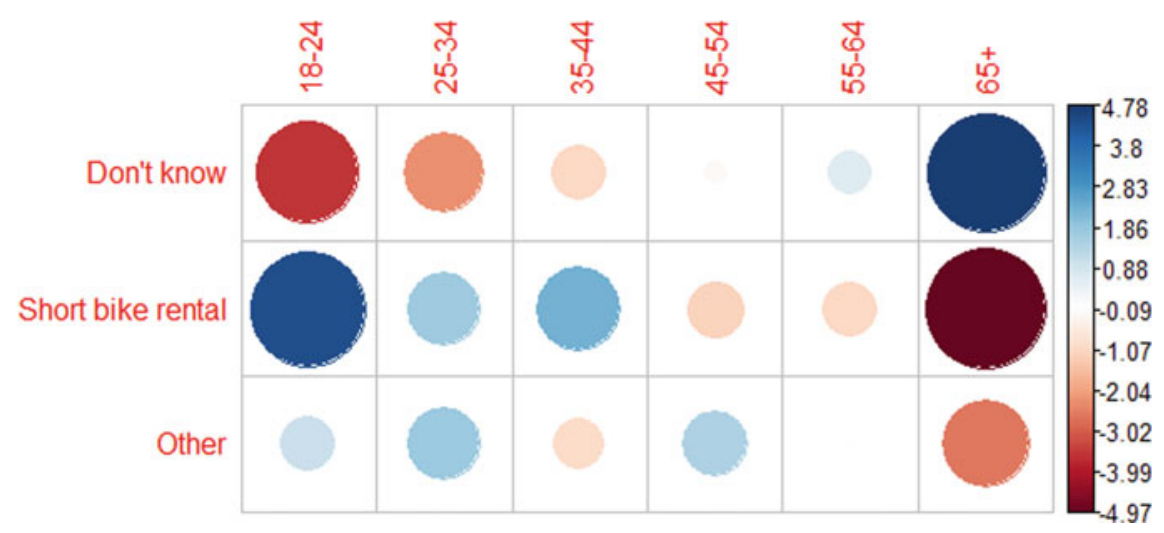

Fig. 4 Pearson residuals for the relationship between 'age' and 'awareness' of bicycle sharing 
use (Fishman, 2016). The association between age and a positive attitude towards bicycle sharing are also consistent with the literature, which shows considerable uptake of shared mobility services by 18-34-year-old groups (Fishman et al., 2015; Shaheen et al., 2012). Similar results were found for the 'awareness' and 'acceptance' of car sharing in Chi-square tests assessing the relationship with the respondents' socio-demographic characteristics, as shown for the relationship between 'age' and 'awareness' in Fig. 5. 'Age', 'employment status' and 'education level' were found to be associated (at a 95\% confidence level) with car-sharing 'awareness' and 'acceptance'. Gender was not found to be an influencing factor. The influence of 'age' and 'education level' follows the same patterns as observed for bicycle sharing: younger versus older age groups, and higher versus lower education have a positive versus negative influence on the awareness and acceptance of car sharing. The results for the influence of 'employment status' show a slightly different picture: respondents who are 'retired/pensioner' or 'housewife/husband' are also here least likely to have a positive attitude, but those in employment, whether 'full time' or 'part time', are the most likely to be aware of and consider using car-sharing services, whereas there is no association with respondents who are 'students' and 'unemployed'.

Tables $2 \mathrm{a}-\mathrm{c}$ presents the results of the respondents' responses as a follow-up to their answer to whether they were willing to use bicycle or car sharing or not (their 'acceptance'). Respondents who replied positively were asked why they considered using bicycle/car sharing (Table 2a). Respondents who replied negatively were asked why they did not consider using the sharing service (Table 2b) and also what might encourage them to use bicycle- or car-sharing services (Table 2c).

Primarily, using bicycle sharing was seen as a form of exercise, producing less traffic and less pollution, whereas for car sharing the reasons were mainly for convenience and time savings, especially when related to parking at busy locations. Respondents seem less convinced about the promise of financial savings from the use of car sharing. The main reasons provided for the lack of use of bicycle sharing are related to knowledge on how to ride a bicycle, a preference to use private transport and the

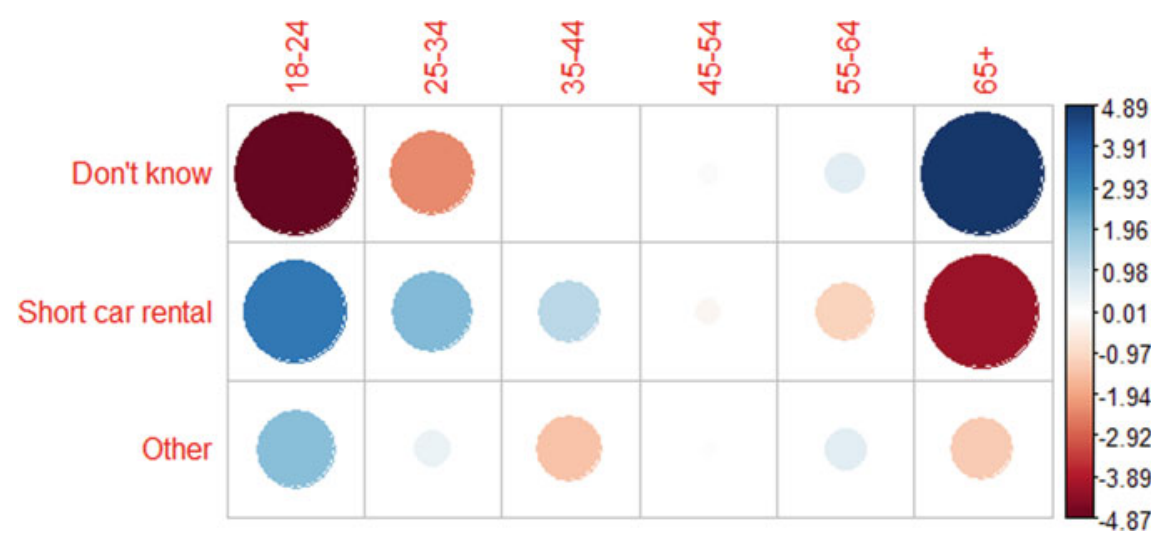

Fig. 5 Pearson residuals for the relationship between 'age' and 'awareness' of car sharing 
Table 2 (a) Reasons for considering using sharing services (b) Reasons for (not) considering using sharing services and (c) Factors that would encourage respondents to consider using sharing services

\begin{tabular}{l|l|l}
\hline & Bicycle sharing & Car sharing \\
\hline (a) & \multicolumn{2}{l}{} \\
\hline Yes, would consider using: & $n=143 \%$ & $n=302 \%$ \\
\hline Less pollution & 41.3 & - \\
\hline Easier parking & 22.4 & - \\
\hline Less traffic & 41.3 & - \\
\hline Saving money & 18.2 & 21.9 \\
\hline For exercise & 42.7 & - \\
\hline Saving time & 9.8 & 39.1 \\
\hline For convenience & 11.2 & 56.6 \\
\hline (b) & &
\end{tabular}

(b)

\begin{tabular}{l|l|l}
\hline No, would not consider using: & $n=957 \%$ & $n=798 \%$ \\
\hline Price & 2.0 & 4.6 \\
\hline Waste of time & 9.0 & 10. \\
\hline Prefer private transport & 28.1 & 44.5 \\
\hline Family commitments & 23.1 & 12.8 \\
\hline Don't know how to cycle & 43.1 & - \\
\hline Don't drive & - & $34.0 \%$ \\
\hline
\end{tabular}

(c)

\begin{tabular}{l|l|l}
\hline What would encourage you? & $n=957 \%$ & $n=798 \%$ \\
\hline Tax incentives & 2.1 & 5.4 \\
\hline Free use of service & 15.2 & 24.8 \\
\hline Priority lanes, reserved parking & 16.1 & 21.7 \\
\hline Increased safety & 33.1 & - \\
\hline Financial savings & - & 15.3 \\
\hline P\&R, multi-modal connectivity & 4.0 & 6.5 \\
\hline Parking restrictions & 4.5 & 8.0 \\
\hline Paid parking & 1.4 & $1.4 \%$
\end{tabular}

Note:-not included in this section of the survey

other family commitments which would prevent users from shifting to the use of a bicycle. The main reasons for not using car sharing were linked to the preference of using own private transport and the inability to drive a vehicle. The main factor that would encourage respondents to use bicycle sharing was the possible increase in safety for cyclists on the roads. Factors that would encourage car sharing were 'priority lanes and reserved parking', 'free use of service' and 'financial savings'. 


\section{Discussion}

While an effort was made to ensure the survey sample was representative of the islands' population, the approach used gives rise to certain limitations and potential bias. Conducting surveys using fixed-line telephony is an affordable and effective way to approach a population. However, approaching respondents through fixedline telephone numbers only is associated with certain limitations (Bryman, 2016). There is a risk that specific groups of people using shared mobility services are underrepresented. These include the younger and more technology-savvy generations who rely more on mobile phones, the increasing number of foreign (temporary) workers in the IT sector in Malta, and living in rental apartments without a fixed landline. To overcome this, sampling from both a registry of mobile and landline phone numbers (see, for example, Therrien et al., 2014) would have provided for a more diverse sample. Furthermore, while the survey sample included respondents from all over the islands, the bicycle-sharing system is geographically limited and primarily available in the urban centre of the main island Malta. Therefore, a large percentage of those participating in the survey were unlikely to have been exposed to the systems at all. Socio-demographic characteristics, such as age, employment and level of education, have a significant influence on awareness and acceptance of bicycle- and car-sharing services. In the future, campaigns surrounding this topic could narrow their focus on specific target groups that are more likely to use bicycle or car sharing, based on characteristics such as age and place of residence, while ensuring respondents represent a variety of employment and education levels.

The main factor that would encourage further take-up of bicycle sharing is increased safety for cyclists. This is in line with findings from a study in Drama (Greece), where respondents reported the lack of safe cycling infrastructure $(49.1 \%)$ and limited road safety (43.6\%) meant they do not consider cycling as a travel option (Nikitas, 2018). The importance of dedicated cycling infrastructure in promoting (shared) bicycle use is evident from the experiences of other cities in Southern Europe. In Seville (Spain), cycling trips increased from 10,000 to 70,000 trips per day between the period 2006 and 2011, following the creation of a $120 \mathrm{~km}$ bicycle network and the implementation of bicycle sharing in 2007 (Marqués et al., 2015). The introduction of bicycle sharing in 2018 and the extension of the cycling network in Las Palmas de Gran Canaria (Spain) led to 24,000 registered users after the first year of operations (Maas et al., 2020). The creation of segregated cycling paths on main roads, a reduction in speed limits in residential and rural roads, and the raising of awareness about road safety among all road users have established strategies that help to improve cycling safety (Handy et al., 2014; Heinen et al., 2010). The survey results also unearthed the relatively high percentage of people who do not know how to cycle: $37.5 \%$ of respondents in Malta in comparison with $4.7 \%$ of respondents in Drama (Nikitas, 2018). Promoting cycling training across all ages and the implementation of safe routes to school for children can help improve these figures (Handy et al., 2014; Pucher et al., 2010). In fact, Nextbike Malta offers free cycling training through their Bikeability programmes held regularly in different parts of the island. 
However, to date, there is limited dedicated cycling infrastructure (Transport Malta, 2016a).

The survey results show that respondents' main reasons for using car sharing are convenience and time savings. Indeed, respondents who currently do not use car sharing identified the need for priority in traffic and more reserved parking, free (subsidized service) and financial savings as factors that would change their attitude towards these new schemes. Increasing the network of shared priority lanes (reserved for shared and green vehicles) can increase the competitive advantage of shared vehicles, in comparison with the travel times and financial costs that come with using a private car. Survey results show how respondents are not convinced that a shared car may save them money. A campaign to explain the true costs of private car ownership and use when compared to a 'shared' car may be needed to raise further awareness. To encourage a modal shift, it is important to make alternatives available, but also to introduce restrictions on private car use, physically (e.g. by introducing parking restrictions or limiting access) and financially (e.g. by introducing congestion charges or parking fees).

\section{Conclusions}

This chapter examined the levels of awareness and acceptance of shared bicycle and car mobility services in the islands of Malta, through the aggregated results of cross-sectional surveys carried out over time, as well as the factors impacting the willingness to consider using such services, both in positive and negative terms. Younger, highly educated and full-time employed and students are main groups to target for shared mobility services in Malta. There is a strong positive relationship between younger age groups (18-44) and awareness and acceptance of bicycle and car sharing. A higher education level and being a student or full-time employed are also positively correlated.

There is a large share of respondents who are not yet aware or accepting of these new shared mobility services. Providing more information and educating people about the advantages of using shared bicycles or cars, compared to the current dominant private car use, can help in further promoting shared mobility services, specifically for target groups that are expected to be more willing to take up bicycle or car sharing, based on characteristics such as age and place of residence. To convince people to use car sharing, this can include information about monetary savings on travel, as well as time and financial savings through the provision of reserved parking spaces at destination and priority in traffic. Improved road safety and safe cycling infrastructure can have a significant impact on the use of bicycle sharing. Investment in cycling education and the creation of safe cycling routes can counter the lack of cycling abilities among the population and provides the necessary encouragement for the use of bicycle sharing as one alternative mode of transport, particularly for short trips. 


\section{References}

Ang, G., \& Marchal, V. (2013). Mobilising private investment in sustainable transport: The case of land-based passenger transport infrastructure. OECD Publishing.

Attard, M., Von Brockdorff, P., \& Bezzina, F. (2015). The external costs of passenger and commercial vehicles use in Malta. Institute for Climate Change and Sustainable Development. University of Malta-European Commission Representation in Malta, Msida.

Bryman, A. (2016). Social research methods (5th ed.). Oxford University Press.

Car Sharing Services Malta Ltd. (2019). GoTo car sharing website. Retrieved April 16, 2020 from http://www.goto.com.mt.

Castillo-Manzano, J., Castro-Nuño, M., \& López-Valpuesta, L. (2015). Analyzing the transition from a public bicycle system to bicycle ownership: A complex relationship. Transportation Research Part D: Transport and Environment, 38, 15-26.

Cavallaro, F., Galati, O. I., \& Nocera, S. (2017). Policy strategies for the mitigation of GHG emissions caused by the mass-tourism mobility in coastal areas. Transportation Research Procedia, $27,317-324$.

CIVITAS Initiative (2013). CIVITAS DESTINATIONS project website. Retrieved April 16, 2020 from http://civitas.eu/destinations.

DeMaio, P. (2009). Bike-sharing: History, impacts, models of provision, and future. Journal of Public Transportation, 12(4), 41-56.

European Commission (2013). Attitudes of Europeans towards urban mobility. Special Eurobarometer 406.

Fishman, E., Washington, S., Haworth, N., \& Watson, A. (2015). Factors influencing bike share membership: An analysis of Melbourne and Brisbane. Transportation Research Part A: Policy and Practice, 71, 17-30.

Fishman, E. (2016). Bikeshare: A review of recent literature. Transport Reviews, 36(1), 92-113.

Handy, S., Van Wee, B., \& Kroesen, M. (2014). Promoting cycling for transport: Research needs and challenges. Transport Reviews, 34(1), 4-24.

Heinen, E., Van Wee, B., \& Maat, K. (2010). Commuting by bicycle: An overview of the literature. Transport Reviews, 30(1), 59-96.

Jonuschat, H., Stephan, K., \& Schelewsky, M. (2015). Understanding multimodal and intermodal mobility. In M. Attard, Y. Shiftan, (Eds.), Sustainable Urban Transport(pp. 149-176). Bingley: Emerald Group Publishing Limited.

Le-Klähn, D.-T., \& Hall, C. M. (2015). Tourist use of public transport at destinations-a review. Current Issues in Tourism, 18(8), 785-803. https://doi.org/10.1080/13683500.2014.948812.

Maas, S., Attard, M., \& Caruana, M. A. (2020). Assessing spatial and social dimensions of shared bicycle use in a Southern European island context: The case of Las Palmas de Gran Canaria. Transportation Research Part A: Policy and Practice, 140, 81-97.

Malta Public Transport (2019). Tallinja bike website. Retrieved April 16, 2020 from http://www. publictransport.com.mt/en/tallinja-bike.

Marqués, R., Hernández-Herrador, V., Calvo-Salazar, M., \& García-Cebrián, J. (2015). How infrastructure can promote cycling in cities: Lessons from Seville. Research in Transportation Economics, 53, 31-44.

Martin, E. W., \& Shaheen, S. A. (2011). Greenhouse gas emission impacts of Car sharing in North America. IEEE Transactions on Intelligent Transportation Systems, 12(4), 1074-1086.

Nextbike Malta (2019). Nextbike Malta website. Retrieved April 16, 2020 from http://www.nex tbike.com.mt.

Nikitas, A. (2018). Understanding bike-sharing acceptability and expected usage patterns in the context of a small city novel to the context: A story of 'Greek Drama.' Transportation Research Part F: Traffic Psychology and Behaviour, 56, 306-321.

NSO (2017). National household travel survey 2010. National Statistics Office Malta, Valletta.

NSO (2018) Population Statistics (Revisions): 2012-2016. NR022/2018 National Statistics Office, Valletta. 
Pucher, J., Dill, J., \& Handy, S. (2010). Infrastructure, programs, and policies to increase bicycling: An international review. Preventive Medicine, 50, 106-125.

Ricci, M. (2015). Bike sharing: A review of evidence on impacts and processes of implementation and operation. Research in Transportation Business \& Management, 15, 28-38.

Shaheen, S. A., Guzman, S., \& Zhang, H. (2010). Bikesharing in Europe, the Americas, and Asia: Past, present, and future. Transportation Research Record: Journal of the Transportation Research Board, 2143, 159-167.

Shaheen, S. A., Martin, E. W., Chan, N. D., Cohen, A. P., \& Pogodzinsk, M. (2012). Public Bikesharing in North America: Early Operator and User Understanding (Rep. No. 11-19). San Jose, CA, Mineta Transportation Institute

Shaheen, S. A., \& Chan, N. D. (2016). Mobility and the sharing economy: Potential to facilitate the first-and last-mile public transit connections. Built Environment, 42(4), 573-588.

Therrien, S., Brauer, M., Fuller, D., Gauvin, L., Teschke, K., \& Winters, M. (2014). Identifying the leaders: Applying diffusion of innovation theory to use of a public bike share system in Vancouver, Canada. Transportation Research Record, 2468, 74-83.

Transport Malta (2011). National household travel survey 2010. Malta. Retrieved October 9, 2020 from https://www.transport.gov.mt/NHTS2010-Report-pdf_20120502091559.pdf-f1687.

Transport Malta (2016a). Transport Master Plan 2025. Malta. Retrieved October 9, 2020 from https://www.transport.gov.mt/strategies/strategies-policies-actions/national-transp ort-strategy-and-transport-master-plan-1343.

Transport Malta (2016b). National Transport Strategy 2050. Malta. Retrieved October 9, 2020 from https://www.transport.gov.mt/strategies/strategies-policies-actions/national-transp ort-strategy-and-transport-master-plan- 1343.

Woodcock, J., Tainio, M., Cheshire, J., O’Brien, O., \& Goodman, A. (2014). Health effects of the London bicycle sharing system: health impact modelling study. BMJ, 348, 11 (Clinical Research Ed.).

Open Access This chapter is licensed under the terms of the Creative Commons Attribution 4.0 International License (http://creativecommons.org/licenses/by/4.0/), which permits use, sharing, adaptation, distribution and reproduction in any medium or format, as long as you give appropriate credit to the original author(s) and the source, provide a link to the Creative Commons license and indicate if changes were made.

The images or other third party material in this chapter are included in the chapter's Creative Commons license, unless indicated otherwise in a credit line to the material. If material is not included in the chapter's Creative Commons license and your intended use is not permitted by statutory regulation or exceeds the permitted use, you will need to obtain permission directly from the copyright holder. 